\title{
Influences of Tip Cooling Injection on Tip Clearance Control at Design and Off-Design Incidences
}

\author{
Maosheng Niu and Shusheng Zang \\ School of Mechanical Engineering, Institute of Turbomachinery, Shanghai JiaoTong University, Shanghai 200240, China \\ Correspondence should be addressed to Maosheng Niu, niumaosheng@hotmail.com
}

Received 28 February 2009; Revised 26 June 2009; Accepted 11 July 2009

Recommended by Terrence Simon

\begin{abstract}
A numerical investigation has been performed to study the influences of cooling injection from the blade tip surface on controlling tip clearance flow in an unshrouded, high-turning axial turbine cascade. Emphasis is put on the analysis of the effectiveness of tip injection when the approaching flow is at design and off-design incidences. A total of three incidence angles are investigated, $-7.4^{\circ}$, $0^{\circ}, 0^{\circ}, 0^{\circ}$, and $7.6^{\circ}, 0^{\circ}$ relative to the design value. The results indicate that even at the off-design incidences, tip injection can also act as an obstruction to the tip clearance flow and weaken the interaction between the passage flow and the tip clearance flow. It is also found that tip injection causes the tip clearance loss to be less sensitive to the incidences. Moreover, with injection, at all these incidences the heat transfer conditions are improved significantly on the blade tip surface in the middle and aft parts of blade. Thus, tip injection is proved to be an effective method of controlling tip clearance flow, even at off-design conditions. Beside that, an indirect empirical correlation is observed to be able to perform well in predicting the losses induced by tip clearance flow at design and off-design conditions, no matter whether air injection is active or not.
\end{abstract}

Copyright (C) 2009 M. Niu and S. Zang. This is an open access article distributed under the Creative Commons Attribution License, which permits unrestricted use, distribution, and reproduction in any medium, provided the original work is properly cited.

\section{Introduction}

In axial turbines, a finite clearance is necessary to allow the relative motion between rotor tips and the casing wall, which is nominally $1 \%$ of the rotor span. The pressure difference between the pressure surface and the suction surface drives some passage flow to pass through this clearance, forming tip clearance flow. Tip clearance flow is believed to be detrimental to turbine performance. The work output of the rotor is reduced because the leakage flow passes through the tip clearance without being properly turned and expanded. Moreover, tip clearance flow emerges from the tip gap at an incidence to the passage flow, acting as an obstruction and leading to loss generation within the rotor passage. Booth et al. [1] stated that a tip clearance of about $1 \%$ of the rotor span could cause a loss of $1 \sim 3 \%$ on stage efficiency. Furthermore, flow separation and reattachment on the blade tip surface induce higher heat load to the blade tip regions. Metzger and Rued [2] performed fundamental studies and showed that tip clearance flow generated increases in the heat transfer of about $200 \%$ near the tip clearance.
Thus, several strategies for desensitization of tip clearance flow have been published over the past decades, and among them the common objective is to reduce as much as possible the mass flow that passes through the tip clearance.

The most common method is to modify blade tip geometry to change the discharge coefficient without affecting the pressure distribution around blade tip regions. Saha et al. [3] and Dey and Camci [4] evaluated numerically and experimentally the effects of adding winglets. They reported that with winglets, the strength of tip clearance flow and local heat transfer coefficient on the blade tip surface were reduced remarkably. Azad et al. [5] surveyed squealer tips in a linear cascade arrangement at different Reynolds and Mach number conditions. He observed that squealer tips produced much lower aerodynamic losses for all his cases due to a weaker tip clearance vortex and reduced mixing losses. Bunker and Bailey [6] stated that squealer tips provided an overall lower heat transfer coefficient around blade tip regions. When cavity depth increased, cavity surface heat transfer coefficient decreased and became more uniform. Mischo et al. [7] observed that the total heat transfer Nusselt 
number on the blade tip surface of a 1.5-stage turbine was dramatically reduced, by $15 \%$, when an appropriate profiling of the recess shape was applied. Experimental results also showed that the overall performance of the turbine was improved by 0.2 percent points with recess shape profiling. Numerical research on tip desensitization by tip surface chamfering (Tallman and Lakshminarayana [8]) indicated that chamfering the blade tip near the trailing edge of the gap led to a decrease in the size of the tip clearance vortex and its associated losses. Morphis and Bindon [9] found that rounding of the pressure-side corner could improve totaltotal stage efficiency when the tip clearance height was in the $1 \sim 2 \%$ rotor span range.

Another approach showing potential success for controlling tip clearance flow and cooling the blade tip regions should be air injection. Wei et al. [10] numerically simulated cooling injection from the blade tip surface. He suggested that the jet could obstruct tip clearance flow and weaken the interaction between tip clearance flow and main passage flow, improving turbine efficiency by $0.41 \%$ when the tip clearance is small. Rao and Camci $[11,12]$ studied tip cooling injection in a rotating turbine research facility. He concluded that cooling injection could cause the tip clearance vortex to be reduced, and its associated losses decreased to the level observed for the case with half the gap height. Newton et al. [13] measured the heat transfer coefficient on the tip of a generic cooled turbine blade and confirmed the reduction of heat flux to the blade tip regions. Hamik and Willinger [14] connected the blade leading edge and the blade tip surface using an internal channel, therefore, a small part of passage flow was injected from the blade tip surface forced by the pressure difference. He found that tip injection could weaken flow deviation from the design value near the casing wall, as well as the losses due to the tip clearance vortex.

Nowadays, some modern, unshrouded turbine blades have some sort of squealer tips. Behr et al. [15] and Mischo et al. [16] investigated the effects of tip injection on heat transfer conditions on a squealer tip. They stated that due to the combined effect of squealer tip and coolant injection, significant improvement could be obtained on the cavity floor and inner rim walls. A larger cavity depth or higher blowing ratios could give higher effectiveness on all the tip surfaces.

It is common for a low-pressure turbine stage to operate at significant off-design values of incidence. Tallman and Lakshminarayana [17] and Maosheng and Shusheng [18] believed that tip clearance flow is sensitive to incidence angle. However, those former researchers mainly focused on the influences of air injection under design conditions, fewer investigations have been conducted to survey the potential benefits of air injection at off-design conditions. The current work aims to analyze the single influences of tip cooling injection on a flat tip at off-design conditions, to verify the effectiveness of tip injection at these conditions. The distributions of total pressure loss coefficient at the cascade exit at these off-design conditions, as well as the thermal benefits from tip cooling injection are compared to those at the design condition. Beside that, velocity profiles at the tip clearance entrance and the tip clearance mass
TABLE 1: Cascade geometric parameters.

\begin{tabular}{lc}
\hline Blade span H/mm & 120 \\
Blade chord C/mm & 77 \\
Blade axial chord Cax/mm & 60 \\
Blade pitch s/mm & 55 \\
Tip clearance t/mm & 2 \\
Turning angle/deg & 119 \\
Zweifel number & 1.01 \\
Inlet flow angle/deg & 52.4 \\
Outlet flow angle/deg & -66.6 \\
Injection mass flow/passage mass flow & $1 \%$ \\
Injection plenum pressure/KPa & 230 \\
\hline
\end{tabular}

flow are considered. Such values are not easily measured in experiments. In the end, various empirical correlations are presented and compared with the simulation results, to obtain a better prediction method.

\section{Tip Cooling Injection Configurations}

The turbine cascade considered is modeled based on the mid-span profile of a highly loaded, low aspect ratio, 1.5stage axial turbine (LISA) rotor blade, which has been developed within the Turbomachinery Laboratory of ETH Behr et al. [19]. The tip clearance height is $2 \mathrm{~mm}$, which is $1.667 \%$ of the blade span in the cascade arrangement. The turbine cascade geometric parameters are listed in Table 1.

In the current study, three different incidence angles were tested, $-7.4^{\circ}, 0^{\circ}$, and $7.6^{\circ}$ relative to the design value. The injection system is illustrated in Figure 1. Cooling air entered the plenum chamber and homogenized there, then it was injected into the tip clearance passing through 11 holes which were $1 \mathrm{~mm}$ in diameter. At all conditions, holes on the blade tip surface were located at a distance of $3 \mathrm{~mm}$ from the pressure-side corner, directing toward the blade pressureside corner at an angle of $30^{\circ}$ relative to the blade tip surface. The injection mass flow rate was $1 \%$ of the turbine cascade mass flow.

\section{Numerical Details}

3.1. Numerical Technique. The simulations reported in the current investigation were performed with the commercial software package FINE/Turbo, which solved the threedimensional, Reynolds-averaged, Navier-Stokes equations. Time discretization was accomplished by an explicit fourstage Runge-Kutta scheme. The discretization in space was performed using a second-order central discretization scheme with a fourth-order artificial dissipation. A combination of multi-grid and implicit residual smoothing was used for convergence acceleration. The convergence criterion was set as 1e-6.

A structured grid was employed and the main passage was decomposed into 7 blocks, with O-blocks utilized around the blades to ensure high grid quality. The dimensionless distance, $Y+$, on blade surfaces and casing wall was about 0.5 , and 21 nodes were placed in the boundary layer 


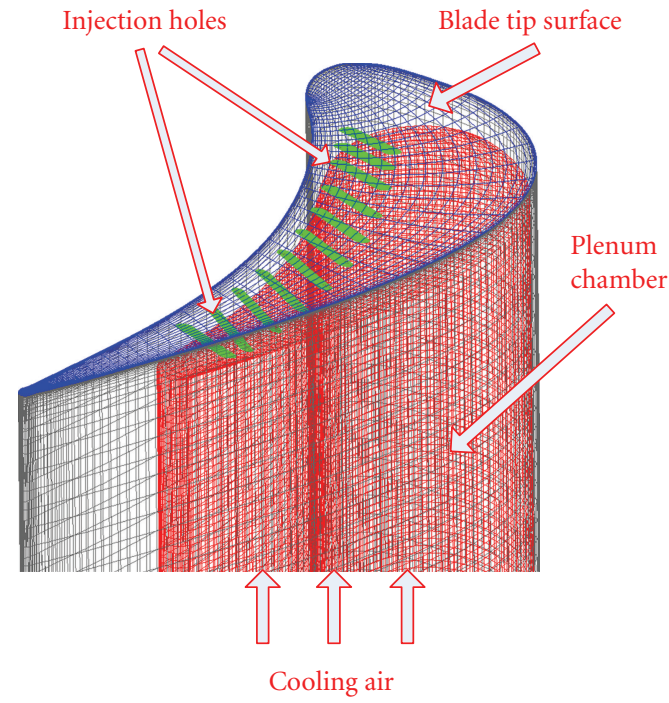

(a)

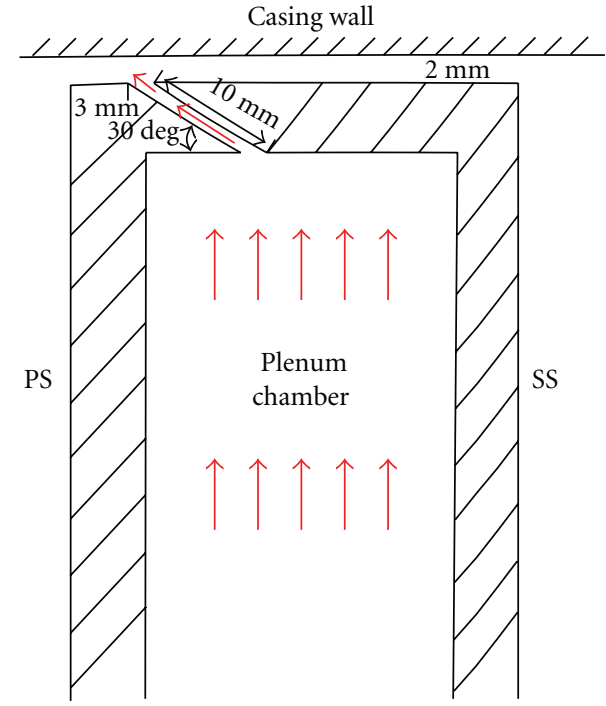

(b)

FIgURE 1: Schematic diagram of injection system.

to provide grid-independent results. The tip clearance was modeled with butterfly mesh topology, and 25 cell layers were distributed from the blade tip to the casing wall. In addition, 13 grid nodes per holes diameter $(1 \mathrm{~mm})$ had been ensured everywhere inside the injection holes, with 33 nodes in the hole length direction $(10 \mathrm{~mm})$. The total grid number was 3.2 million, including 0.4 million in the block of tip clearance.

At the inlet, which was placed at a chord upstream of the leading edge, total pressure, total temperature, and flow angle were specified. The turbulence intensity at the inlet was predefined as $1 \%$. Static pressure was prescribed, which was placed at a distance equal to a chord length downstream of the trailing edge. No-slip isothermal wall conditions were imposed. The inlet of cooling air was treated as inlet, and there the static temperature was set as $290 \mathrm{~K}$. The total pressure at the inlet of air injection was adjusted to ensure that injection mass flow rate was $1 \%$ of the passage mass flow. The total temperature at the exit of injection holes was approximately $300 \mathrm{~K}, 28 \mathrm{~K}$ lower than the passage flow at the cascade inlet. The Reynolds number was $3.23 \times$ $10^{5}$ based on the outlet velocity and the cascade true chord. The outlet velocity was approximately $96 \mathrm{~m} / \mathrm{s}$ and the outlet Mach number was about 0.24 . Therefore, the flow can be treated as incompressible.

3.2. CFD Validation. In order to choose an appropriate turbulence model, the 1.5-stage axial turbine (LISA) is modeled with three turbulence models, Spalart-Allmaras (S-A), Yang-Shih $\mathrm{K}-\varepsilon(\mathrm{K}-\varepsilon)$, and Shear Stress Transport $\mathrm{K}-\omega$ (SST) turbulence models. Comparisons of turbine main parameters in Table 2 show good agreement between experimental data and all the three CFD data.

The comparisons of total pressure coefficient $\left(C_{\mathrm{pt}}\right)$ at rotor exit are presented in Figure 2(a). It reveals that all the simulations predict the radial position of both the tip clearance vortex and the tip passage vortex accurately. However,
TABle 2: Parameters comparison of the 1.5-stage axial turbine (LISA).

\begin{tabular}{lcccc}
\hline Parameters & Experiment & S-A & K- $\varepsilon$ & SST \\
\hline Pressure ratio & 1.353 & 1.352 & 1.351 & 1.351 \\
Reaction degree & 0.39 & 0.385 & 0.383 & 0.386 \\
Loading coefficient & 2.36 & 2.34 & 2.33 & 2.34 \\
Flow coefficient & 0.65 & 0.633 & 0.634 & 0.629 \\
Efficiency & 0.91 & 0.9109 & 0.9126 & 0.9136 \\
\hline
\end{tabular}

both the K- $\varepsilon$ model and the SST K- $\omega$ model underestimate the total pressure loss induced by secondary flow, especially the latter one, approximately 3\% less than the experimental results. As shown in Figure 2(b), the distributions of yaw angle at the rotor exit indicate that the SST K- $\omega$ model underpredicts flow yaw angle in the tip clearance vortex region. All these models under-estimate yaw angle in the tip passage vortex region, particularly the $\mathrm{K}-\varepsilon$ model, and the maximum discrepancy is about $2^{\circ}$. Coinciding with the distributions of $C_{\mathrm{pt}}$ and yaw angle, axial velocity in the tip clearance vortex region using the SST K- $\omega$ model is larger than those when the other two models are utilized, shown in Figure 2(c).

For all the comparisons, these three models agree well with the experimental data. The S-A turbulence model is adopted in the following analysis, rather than the $\mathrm{k}-\varepsilon$ model or the SST k- $\omega$ model, mainly because of its robustness and the lower additional CPU and memory usage.

\section{Results and Discussions}

4.1. Blade Loading Distributions. In Figures 3(a)-3(c), the variations of static pressure coefficient $\left(C_{\mathrm{p}}\right)$ are shown for the cascade with and without tip cooling injection. Results are presented at $98 \%$ span for incidence values of $-7.4^{\circ}, 0^{\circ}$, and $7.6^{\circ}$. 


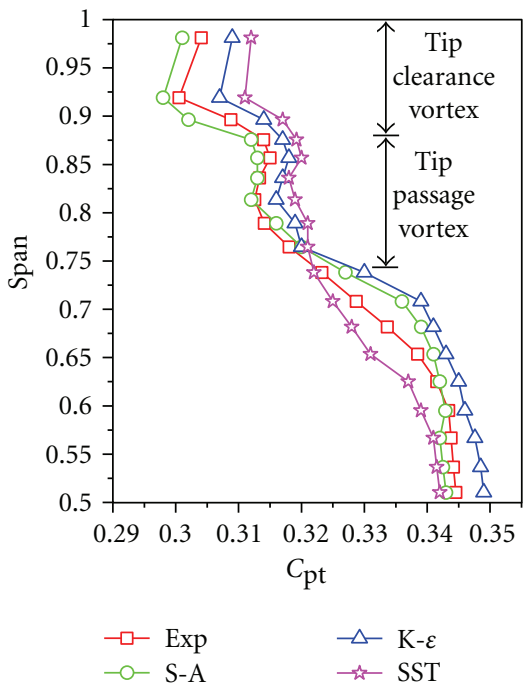

(a)

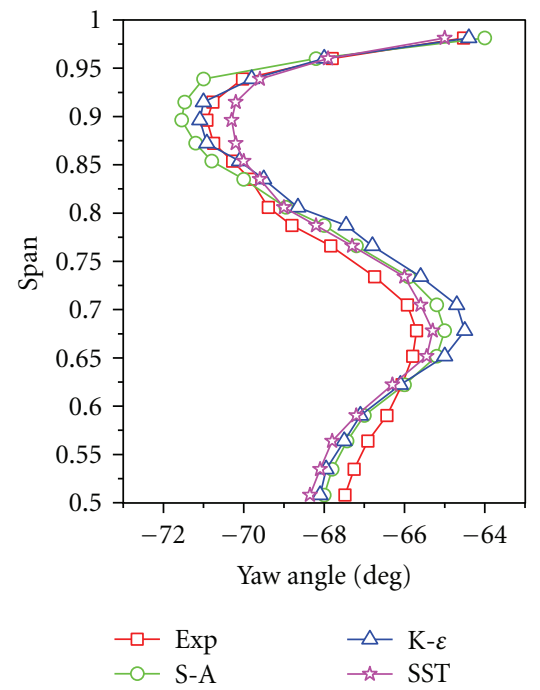

(b)

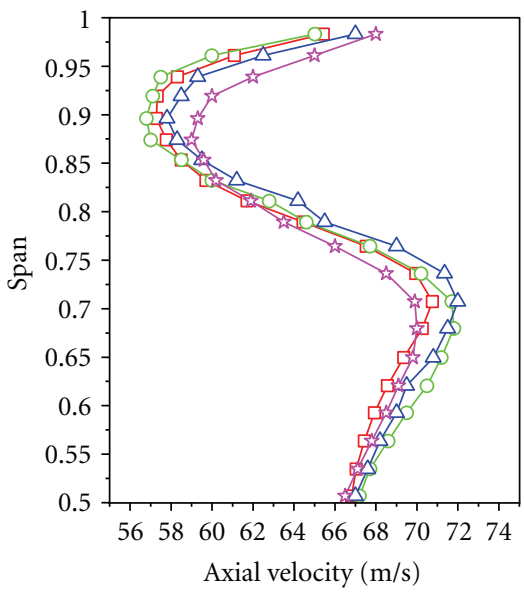

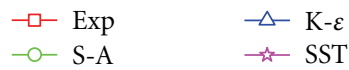

(c)

FIgURE 2: (a) Total pressure coefficient, (b) yaw angle, and (c) axial velocity at rotor exit, pitchwise mass-averaged.

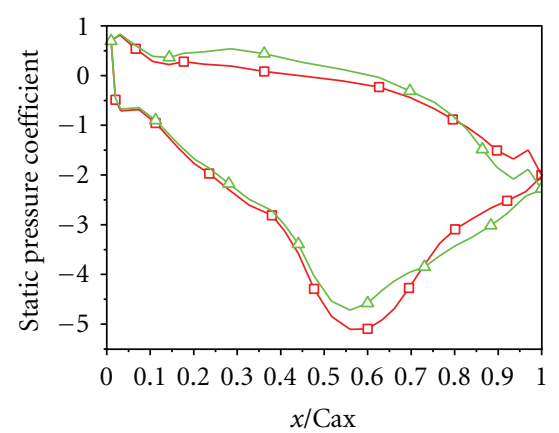

$-\square-i=-7.4 \mathrm{deg}$, no injection

$\triangle-i=-7.4$ deg, injection

(a)

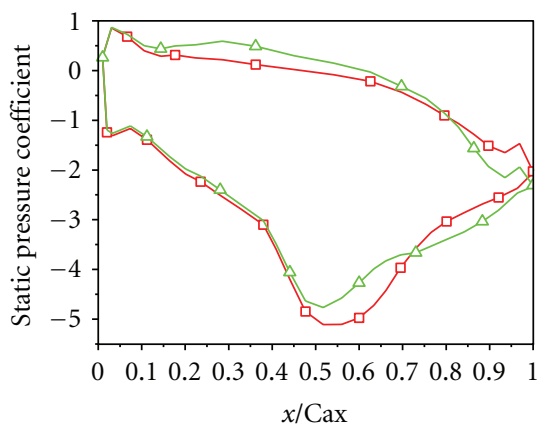

$\neg-i=0 \mathrm{deg}$, no injection

$\triangle \quad i=0$ deg, injection

(b)

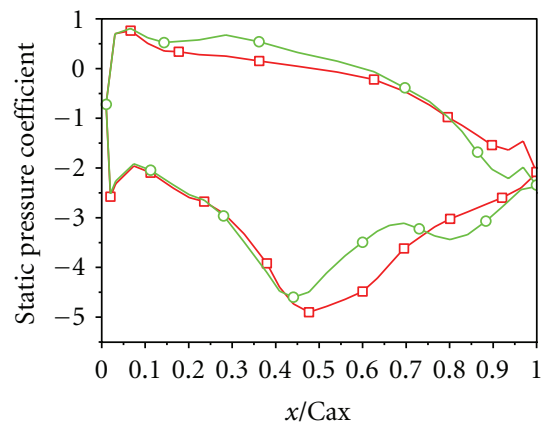

$\neg-i=7.6 \mathrm{deg}$, no injection

$\triangle \quad i=7.6 \mathrm{deg}$, injection

(c)

Figure 3: Distributions of static pressure coefficient $\left(C_{\mathrm{p}}\right)$ at $98 \%$ span (a) $i=-7.4^{\circ}$, (b) $i=0^{\circ}$, (c) $i=7.6^{\circ}$.

Without air injection, shown in Figure 3(b), it can be seen the suction peak is located at about $0.56 \mathrm{Cax}$ at the design condition. Therefore, the cascade profile can be considered to be aft-loaded. Around the blade tip regions, a lower-pressure zone caused by the tip clearance vortex appears on the aft part of the suction surface. As the tip clearance vortex moves away from the suction surface, its influence decreases. At the positive incidence, the lowerpressure zone shifts towards the leading edge to about $0.47 \mathrm{Cax}$, which is a result of the more upstream formation of the tip clearance vortex.

With air injection, the static pressure increases on the front part of the pressure surface and decreases near the trailing edge. This can be attributed to the axial delay of the tip clearance vortex caused by the obstruction due to tip injection. In all cases, significant increases of static pressure on the suction surface due to the reduced tip clearance vortex can be identified, especially at the positive incidence $\left(7 \cdot 6^{\circ}\right)$.
However, in the aft part of the blade, lower $C_{\mathrm{p}}$ still exits than that without air injection, which might also be caused by the appearance of the tip clearance vortex.

Figure 4 shows contours of static pressure coefficients on the blade tip surface. The most significant feature is that in the cases without air injection, steep pressure drops occur along the pressure-side corner, which are even lower than those of the suction-side corner. This is caused by highly accelerated flow at the gap entrance. Bindon [20] measured the static pressure on the blade tip surface in a linear cascade and confirmed the existence of the pressure drop. Bindon [21] concluded that it was associated with flow separation from the pressure side edge and located underneath the tip separation vortex. With an incidence value of $-7.4^{\circ}$, the lower pressure region is the shortest in the chordwise direction. As the incidence angle rises, the chordwise extent occupied by the lower $C_{\mathrm{p}}$ also increases. At the positive incidence $\left(7.6^{\circ}\right)$, this region is observed to extend almost to 


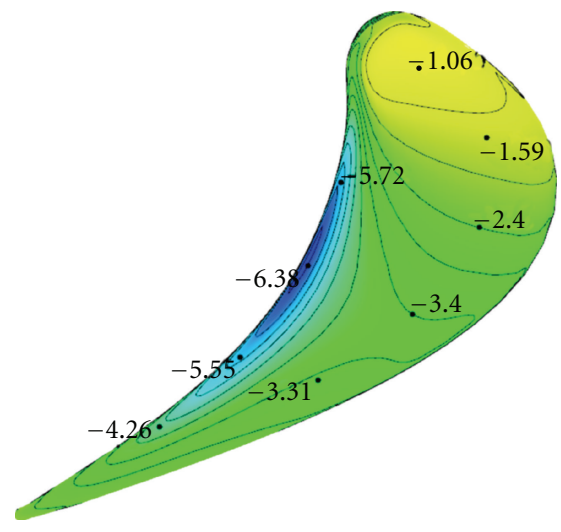

(a) $i=-7.4^{\circ}$, no injection

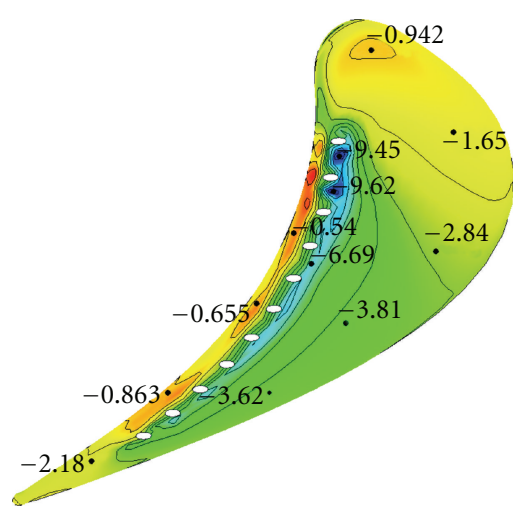

(d) $i=-\operatorname{deg}^{\circ}$, injection

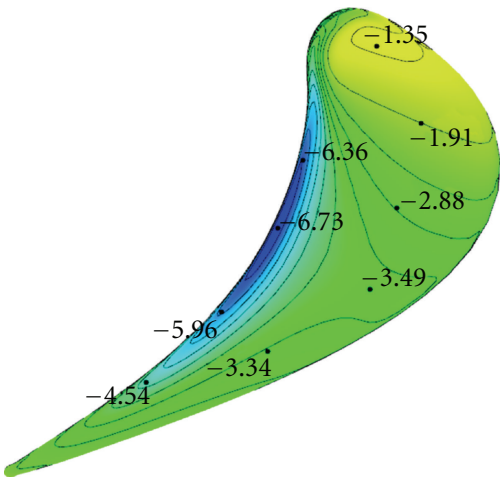

(b) $i=0^{\circ}$, no injection

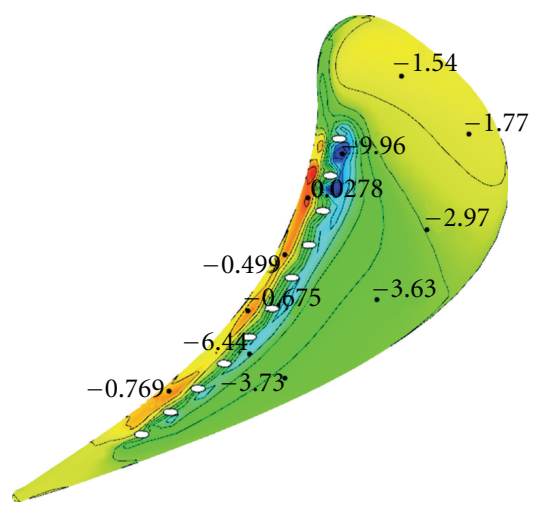

(e) $i=0^{\circ}$, injection

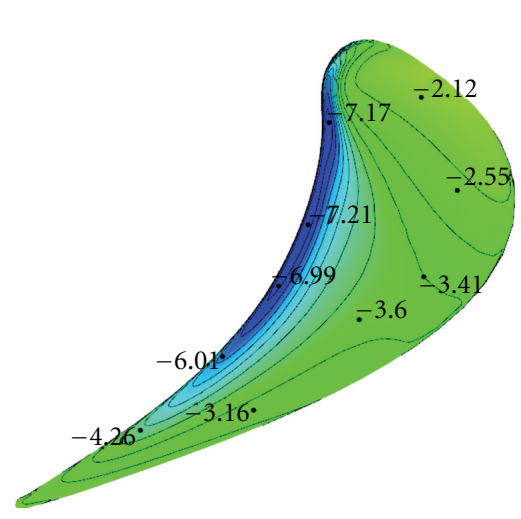

(c) $i=7.6^{\circ}$, no injection
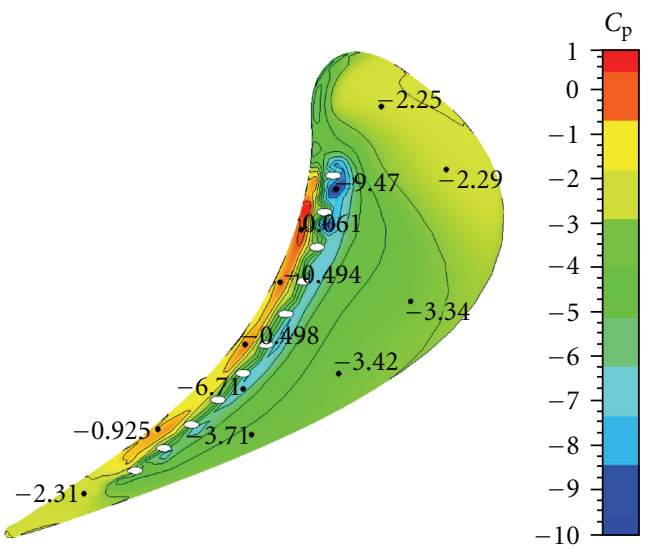

(f) $i=7.6^{\circ}$, injection

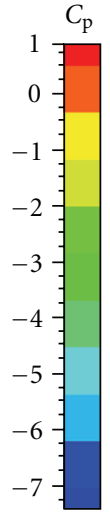

FIgURE 4: Distribution of static pressure coefficient on the blade tip surface.

the leading edge and values of $C_{\mathrm{p}}$ in this region becomes smaller, which can also prove the earlier formation of the tip clearance vortex. At all these conditions, a region of relatively high $C_{\mathrm{p}}$ is observed near the leading edge, where there is less pressure difference to drive flow across the tip clearance gap.

With air injection, the static pressure along the pressure side corner rises dramatically at all the conditions, caused by the blocking effect of the jet. However, much lower static pressure occurs in the regions downstream of the injection locations, especially near to the first two holes, which might be because that higher speed occurs at the exit of the holes. Moreover, a comparison among Figures 4(d), 4(e), and 4(f) shows that even at off-design incidences, tip injection could affect the distribution of static pressure in the middle and the aft parts of the blade almost the same as at the design conditions.

4.2. Total Pressure Loss Coefficient at Cascade Exit. The total pressure loss coefficient is defined as:

$$
C_{\mathrm{po}}=\frac{\left(\bar{P}_{o, 1}-P_{o}\right)}{\left(0.5 \rho V_{\mathrm{ave}, 1}{ }^{2}\right)},
$$

where $\bar{P}_{o, 1}$ is the mass-averaged total pressure measured at the cascade inlet when air injection is not active. However, when air injection is applied, $\bar{P}_{o, 1}$ is the mass-averaged total pressure at the cascade inlet and at the plenum chamber, that is,

$$
\bar{P}_{o, 1}=\frac{\left(P_{o, \text { ave }, 1} \times m_{m}+P_{o, i} \times m_{i}\right)}{\left(m_{m}+m_{i}\right)},
$$

$m_{i}, m_{m}$ are injection mass flow rate and main passage mass flow rate, respectively,

$$
m_{i}=1 \% \times m_{m} .
$$

Figure 5 plots distributions of total pressure loss coefficients $\left(C_{\mathrm{po}}\right)$ at 0.1 axial chord lengths downstream of the trailing edge. Three major high-loss regions can be identified. Firstly, regions close to the casing wall are dominated by the tip clearance vortex. Secondly, a high-loss area caused by the tip passage vortex is located much closer to the suction surface and to the mid-span. The third high-loss region is caused by the blade wake. Losses are much larger in the tip clearance vortex region than in the other two regions.

As shown in Figures 5(a), 5(b), and 5(c), without air injection, the influence of incidence angle on the radial position of both the tip clearance vortex and the tip passage vortex can be neglected. However, when incidence angle increases from $-7.4^{\circ}$ to $7.6^{\circ}$, the areas dominated by 


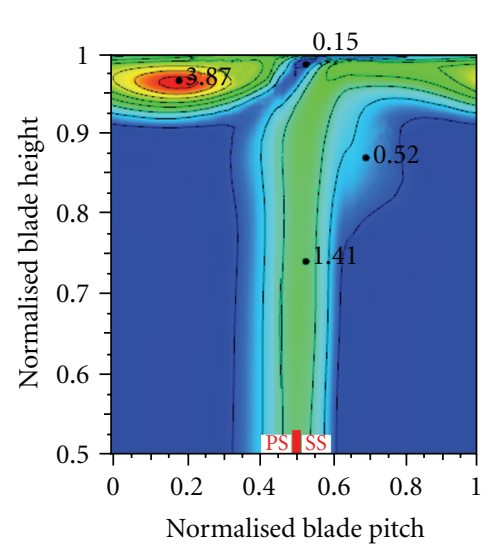

(a) $i=-7.4^{\circ}$, no injection

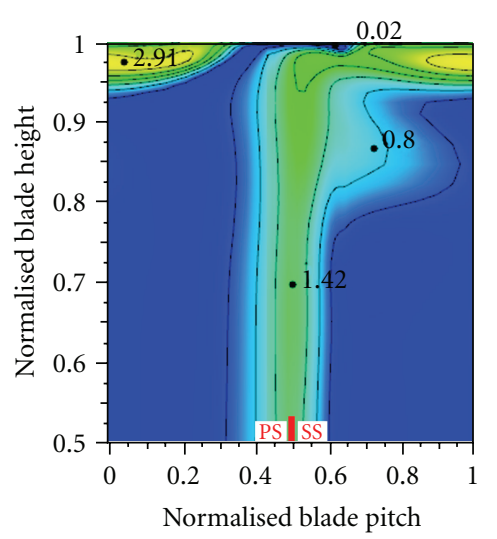

(d) $i=-7.4^{\circ}$, injection

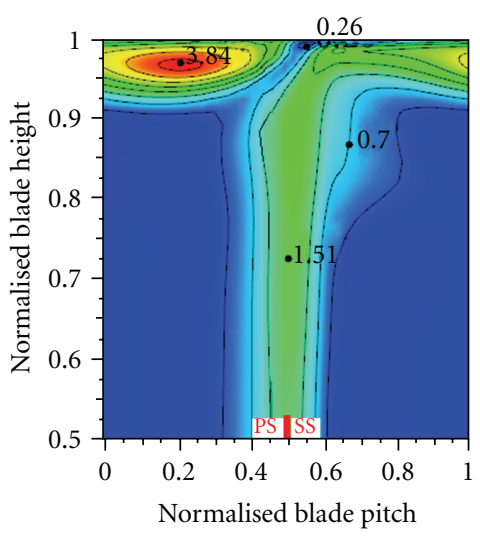

(b) $i=0^{\circ}$, no injection

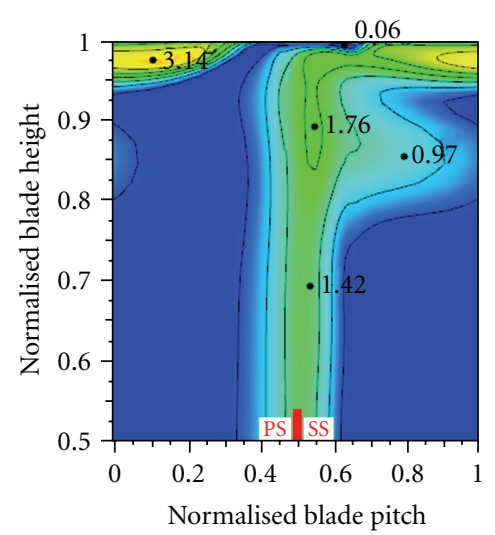

(e) $i=0^{\circ}$, injection
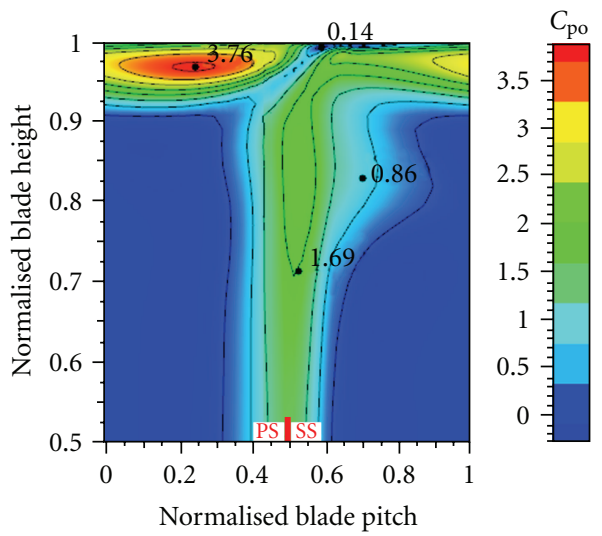

(c) $i=7.6^{\circ}$, no injection
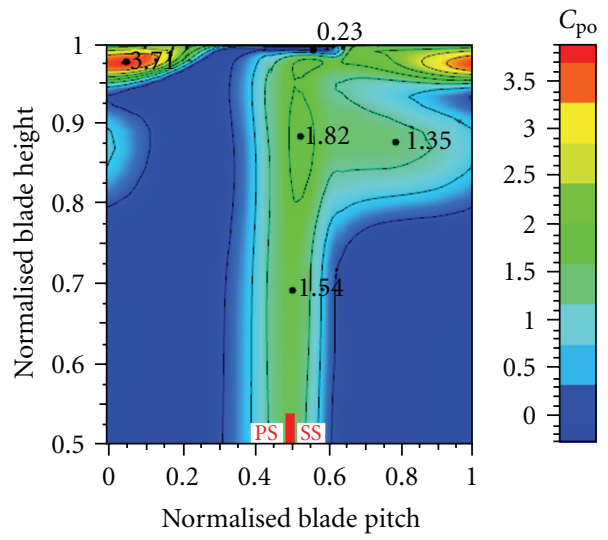

(f) $i=7.6^{\circ}$, injection

FIgURE 5: Distribution of total pressure loss coefficient at cascade exit.

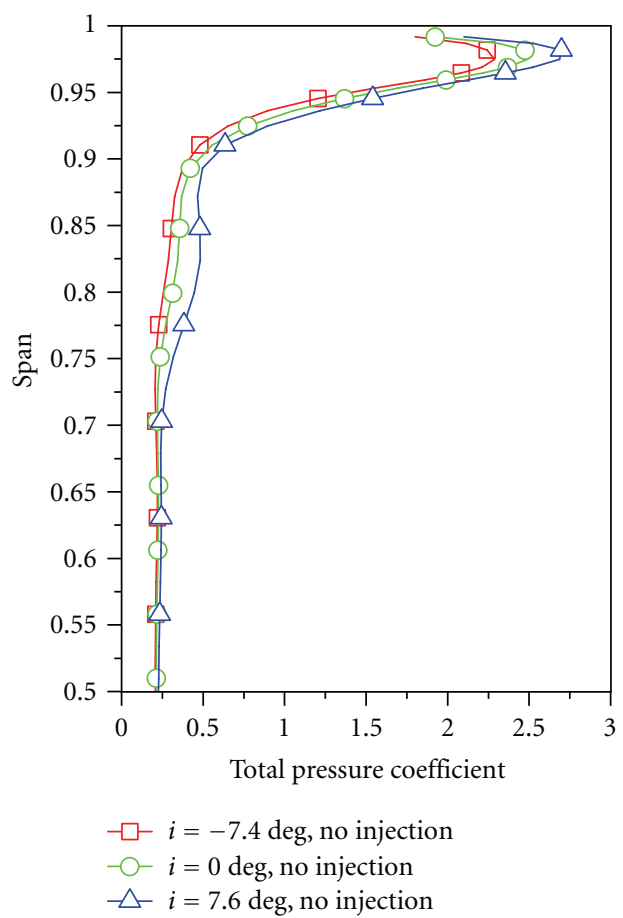

(a) Without tip cooling injection

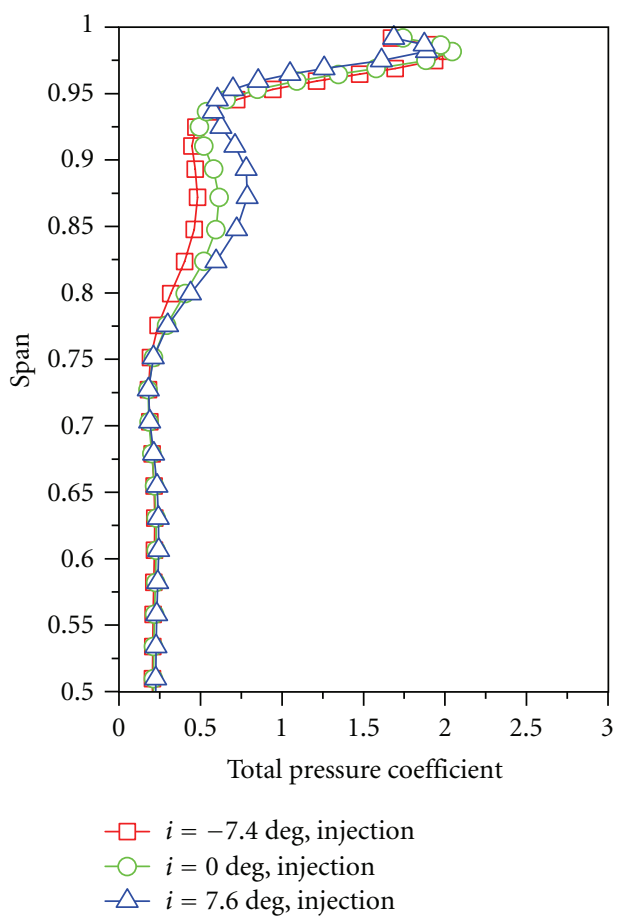

(b) With tip cooling injection

Figure 6: Pitchwise mass-averaged total pressure loss at cascade exit. 


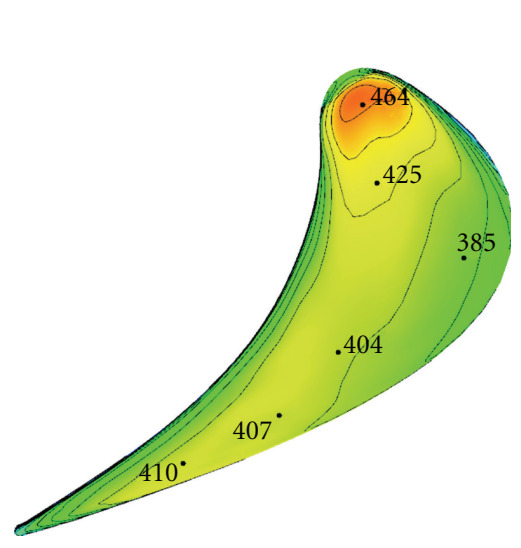

(a) $i=-7.4^{\circ}$, no injection

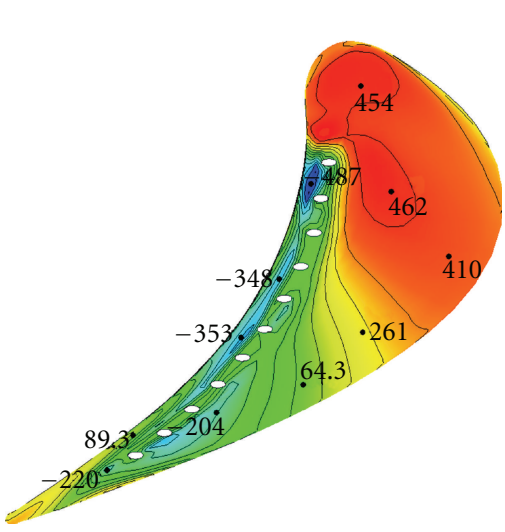

(d) $i=-7.4^{\circ}$, injection

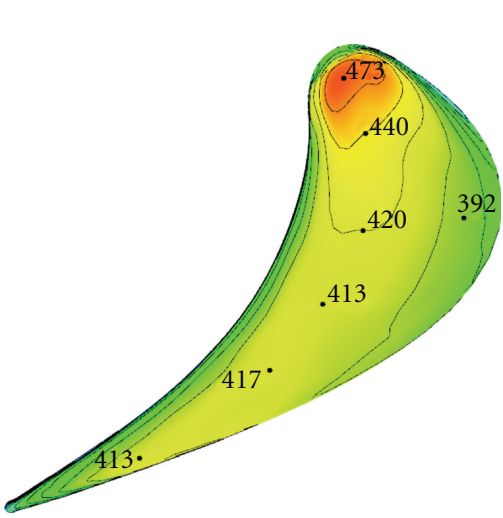

(b) $i=0^{\circ}$, no injection

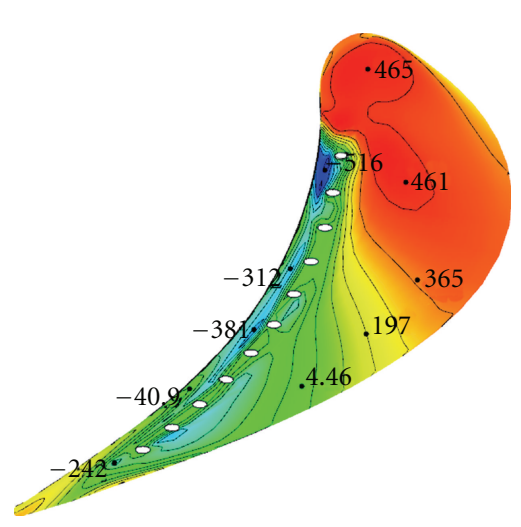

(e) $i=0^{\circ}$, injection

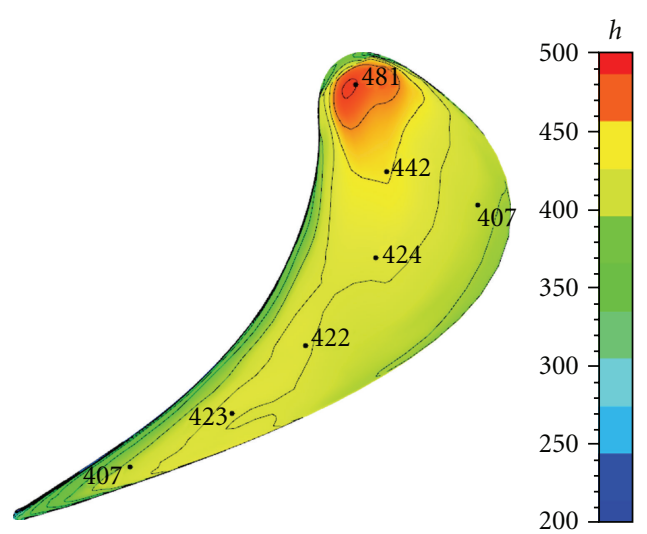

(c) $i=7.6^{\circ}$, no injection

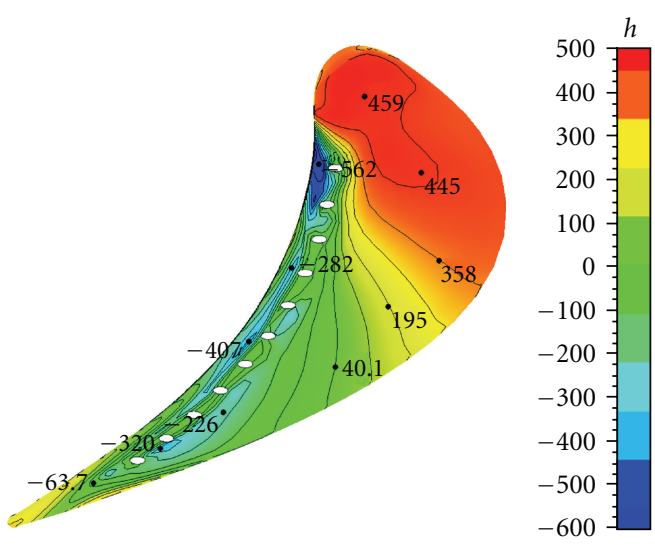

(f) $i=7.6^{\circ}$, injection

FIGURE 7: Distribution of heat transfer coefficient on the blade tip surface.

both the vortices increase in the pitchwise direction. With increases in the incidence, the intensity of the tip clearance vortex decreases slightly while that of the tip passage vortex increases. As a result, the pitchwise mass-averaged total pressure loss rises in both regions with increased incidence angle, as shown in Figure 6(a).

When air injection is applied (Figures 5(d), 5(e), and $5(\mathrm{f})$ ), the vortical structure at the cascade exit is totally altered. The area dominated by the tip clearance vortex decreases significantly, from $8.5 \%$ span to $6.2 \%$ span in the radial direction. The core of the tip clearance vortex shifts towards the endwall and closer to the suction surface. At the positive incidence $\left(7.6^{\circ}\right)$, the tip clearance vortex occurs in the middle of the passage and is much smaller, with a slight decrease in its intensity. However, the size of the tip passage vortex rises dramatically when air injection is active, especially at the incidence value of $7.6^{\circ}$. This is probably due to the combined effects of the same direction of injection as that of the tip passage vortex and the less restriction of the weaker tip clearance vortex.

From Figure 6(b), it can be seen that with air injection, pitchwise mass-averaged loss peaks in the tip clearance vortex region at off-design conditions are both less than that at the design condition. Moreover, the discrepancy between loss peaks caused by the tip clearance vortex in different cases becomes smaller than that without injection, from $17.4 \%$ to about $6.7 \%$. Thus, it is believed that with air injection, tip clearance flow is less sensitive to the incidence angle. However, the discrepancy between losses peaks in the tip passage vortex region increases, as shown in Figure 6(b). It might because that the influences of the tip passage vortex increase as incidence angle increases from $-7.4^{\circ}$ to $7.6^{\circ}$, due to less restriction from the weaker tip clearance vortex.

\subsection{Heat Transfer Coefficient on the Blade Tip Surface.} Contours of the heat transfer coefficients on the blade tip surface at different conditions are exhibited in Figure 7. It can be seen that with and without injection, the maximum heat transfer coefficient appears near the leading edge, where the passage flow is driven into the tip clearance by higher pressure near the stagnation point of the blade. When air injection is applied, the negative heat transfer coefficient appearing on the blade tip surface means that the heat is transferred from the blade tip surface to the cooling jet. At all the incidences, the heat transfer coefficients in the middle and aft parts of blade decrease significantly, particularly in the regions near the injection holes. However, high heat transfer coefficients still occur near the leading edge, where no injection holes are located. With injection, the area with higher heat transfer coefficients expands in the front part 

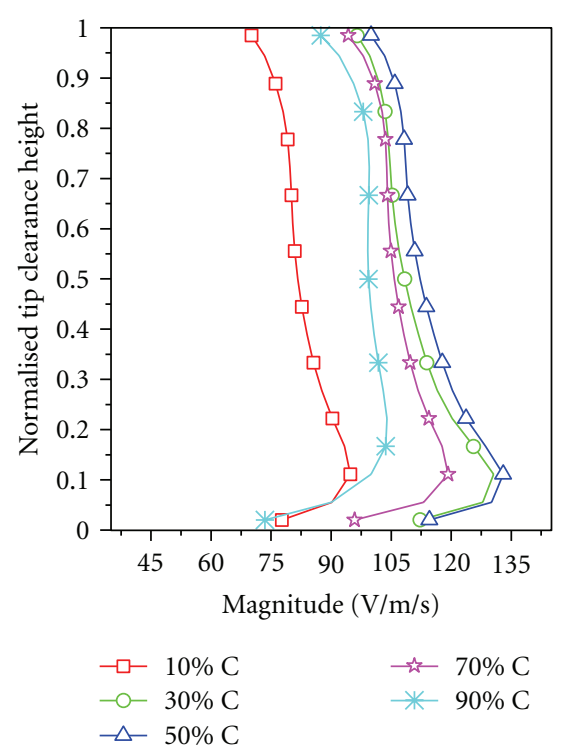

(a) $i=-7.4^{\circ}$, no injection

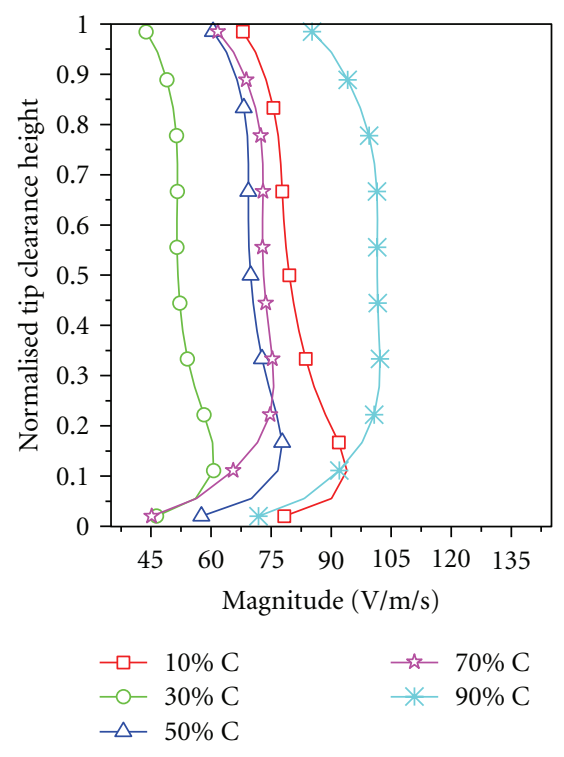

(d) $i=-7.4^{\circ}$, injection

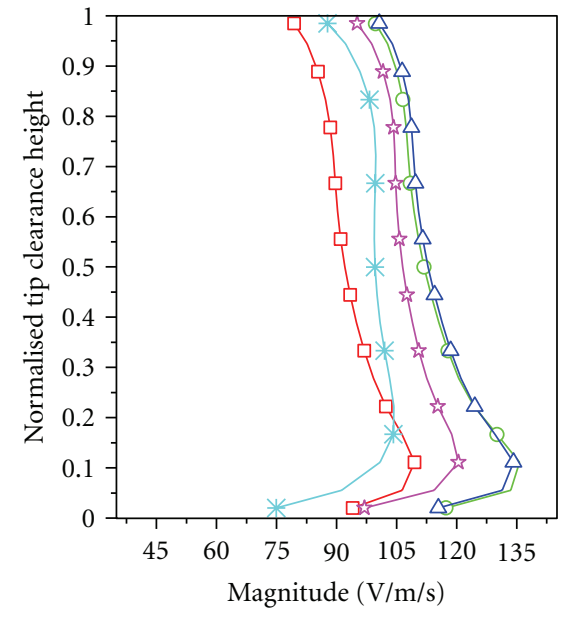

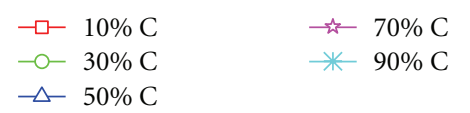

(b) $i=0^{\circ}$, no injection

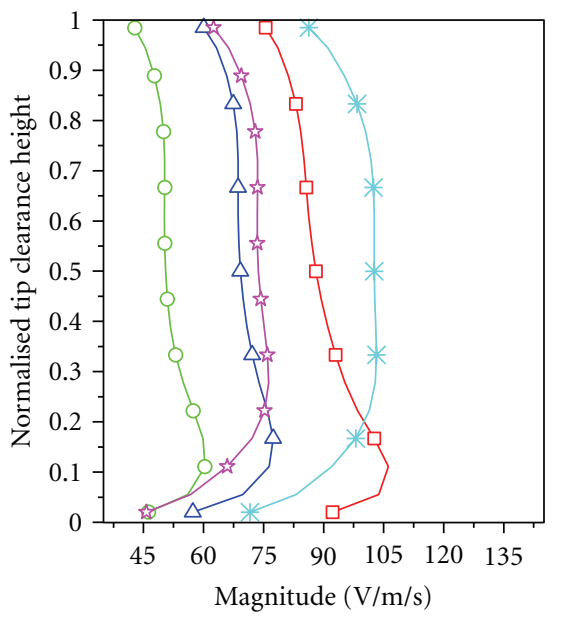
$\rightarrow 10 \% \mathrm{C}$ - $\square-70 \% \mathrm{C}$
$-30 \% \mathrm{C} \quad * 90 \% \mathrm{C}$
$\triangle-50 \% \mathrm{C}$

(e) $i=0^{\circ}$, injection
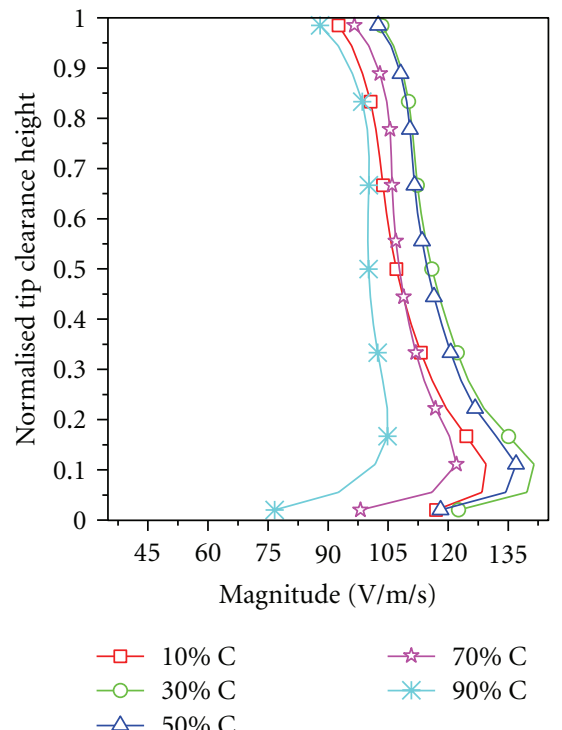

(c) $i=7.6^{\circ}$, no injection

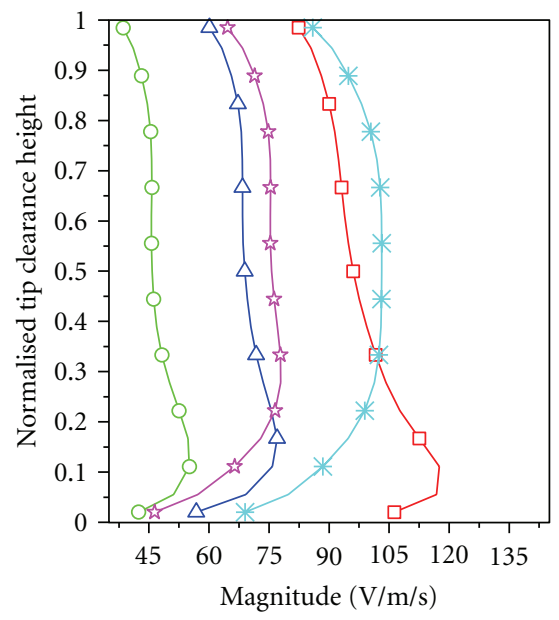

$\rightarrow-10 \% \mathrm{C}$ th $70 \% \mathrm{C}$

$-\mathrm{O}-30 \% \mathrm{C} \quad * \quad 90 \% \mathrm{C}$

$\triangle \backsim 50 \% \mathrm{C}$

(f) $i=7.6^{\circ}$, injection

FIGURE 8: Distribution of velocity profiles at the tip clearance entrance.

of the blade, especially at the negative incidence $\left(-7.4^{\circ}\right)$. Another key feature that can be seen in these figures is that incidence angle has little influence on the distribution of the heat transfer coefficient, no matter whether air injection is active or not.

4.4. Velocity Profiles at Tip Clearance Entrance. Five planes spaced equally from $10 \%$ to $90 \%$ of chord are selected to study the velocity profiles at the tip clearance entrance. The profiles are shown in Figure 8, and the velocity in this figure stands for the velocity component which is perpendicular to the airfoil's camber.

Without air injection, the distributions of velocity in these planes at different incidences are almost the same, except for those near the leading edge. At design incidence, higher velocity mainly occurs at $30 \sim 70 \%$ of chord. When incidence angle increases from $-7.4^{\circ}$ to $7.6^{\circ}$ relative to the design value, velocity profiles in the aft part of blade are affected little, but profiles of the planes near the leading edge increase significantly, which coincides with the distribution of static pressure on the blade tip surface in Figure 4. Thus, the mass flow that passes through the tip clearance increases with incidence.

Due to the obstruction by cooling air injection, at design and off-design incidences, it can be always observed that the velocity at the tip clearance entrance in the middle of blade decreases dramatically. High velocity still occurs near the leading edge and the trailing edge, but they are much lower 


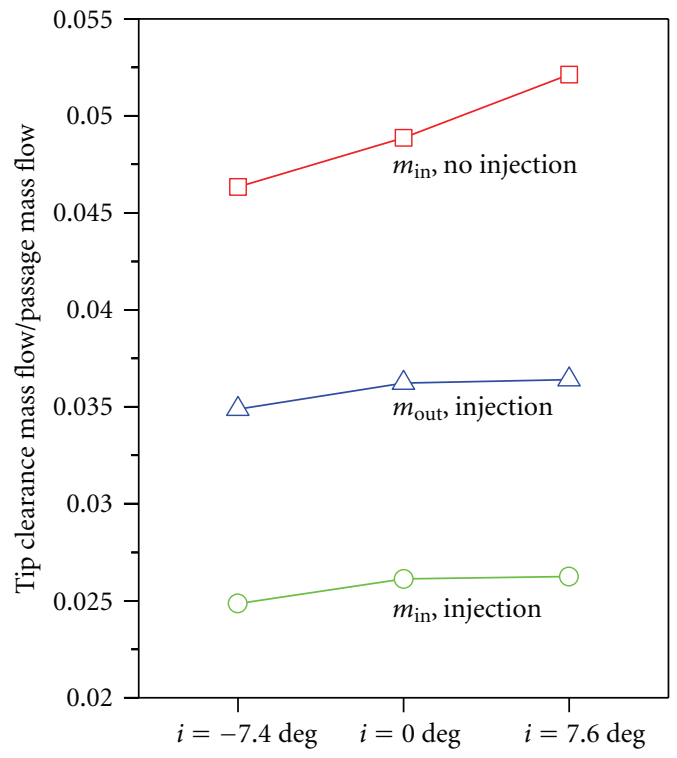

Figure 9: Comparison of tip clearance mass flow at design and offdesign conditions.

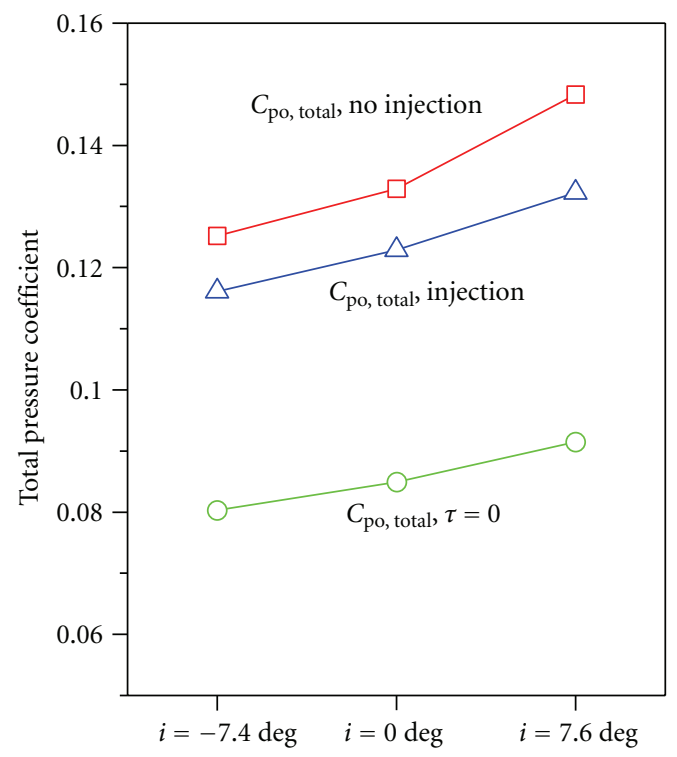

Figure 10: Comparison of the tip clearance losses at design and offdesign conditions.

than velocities in the cases of no injection. As in the cases of no injection, velocities in the planes near the leading edge increase with increased incidence angle, which can be also proved in Figure 4.

4.5. Tip Clearance Mass Flow. As a result of reduced velocities at the tip clearance entrance with injection, the tip clearance mass flow rates would also decrease. Figure 9 gives comparisons of tip clearance mass flow in all cases. It should be noted that in cases with air injection, the mass flow that exits out of the tip clearance from the suction side is greater than that which enters into the tip clearance from the pressure side; the difference is the mass flow of tip injection. Coinciding with the distribution of velocity profiles at the tip clearance entrance, without injection, the tip clearance mass flow increases slightly when incidence angle varies from $-7.4^{\circ}$ to $7.6^{\circ}$. When air injection is applied, mass flow entering into the tip clearance decreases dramatically, from $4.89 \%$ to $2.61 \%$ of the cascade mass flow (at the design incidence). Moreover, it can be found that with air injection, tip clearance mass flow changes little among the different conditions computed.

4.6. Loss Predictions. Typically, the total losses in a blade passage can be subdivided into profile losses, secondary losses and tip clearance losses, which can be expressed as

$$
C_{\text {po,total }}=C_{\text {po,profile }}+C_{\text {po,secondary }}+C_{\text {po,tip }} \text {. }
$$

The tip clearance loss coefficient is obtained from the difference between the total losses with and without tip clearance

$$
C_{\text {po,tip }}=C_{\text {po,total }}-C_{\text {po,total }, \tau=0} .
$$

Based on the comparisons of the total pressure loss at design and off-design incidences (shown in Figure 10), it can be found that when the incidence angle increases from $-7.4^{\circ}$ to $7.6^{\circ}$, the total pressure loss coefficient also increases. It is believed that the large increase in losses is caused by flow separation on the blade suction surface at positive incidence. With air injection, the total losses are caused to be reduced significantly, particularly at positive incidence. Moreover, the total pressure loss coefficient becomes less sensitive to the incidence angle.

In recent years, numerous efforts have been focused on the prediction of the tip clearance losses, in order to clarify the influence factors of tip clearance flow in axial turbines. Table 3 lists several empirical correlations based on turbine rig experiments.

Figure 11 compares the simulated tip clearance losses with the prediction methods of Table 3 . It can be seen that the empirical prediction presented by Ainley and Mathieson [26] estimates the tip clearance losses with and without air injection almost the same. This is because in this correlation the discharge coefficient, which is the most affected factor by air injection is not taken into consideration. The same trends can also be found in the predictions with the Dunham-Came correlation [27] and the Kacker-Okapuu correlation [28].

The Denton correlation [22] can predict the tip clearance losses well at the positive incidence but a large discrepancy can be observed at the other two incidences. Similarly, the Yaras-Sjolander prediction [25] can estimate only the tip clearance losses at negative incidence. The differences between the simulation results and the predictions rise with increased incidence angle.

However, an indirect method proposed by Benner et al. $[23,24]$ shows good agreement with the simulation result in all the cases. In Benner's method, the tip clearance losses are obtained by subtracting the profile losses and the secondary losses from the total losses:

$$
C_{\text {po,tip }}=C_{\text {po,total }}-C_{\text {po,profile }}-C_{\text {po,secondary }},
$$




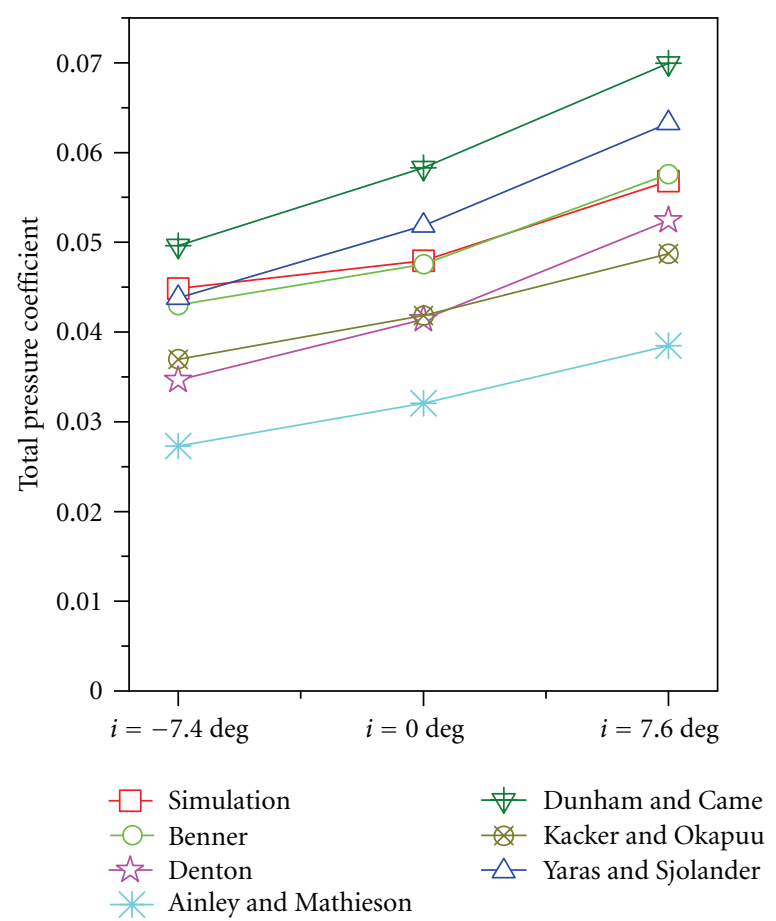

(a) Without injection

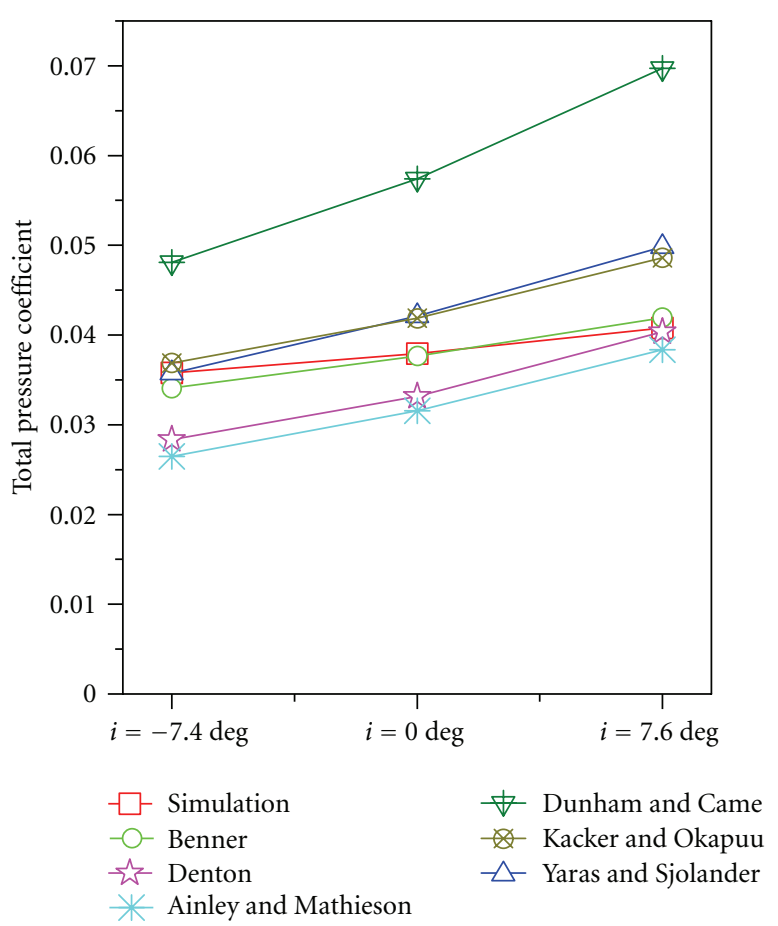

(b) Injection

FIGURE 11: Comparison of the tip clearance losses between the simulation and the empirical predictions.

where the profile losses and the secondary losses are calculated from

$$
\begin{aligned}
& C_{\text {po,profile }} \\
& \quad=\frac{P_{o, \text { mid }, 1}-P_{o, \text { mid }, 2}}{P_{o, \text { mid }, 2}-P_{\text {mid }, 2}}\left(1-\frac{0.10\left(F_{t}\right)^{0.79}}{\sqrt{C R}(H / C)^{0.55}}-32.70\left(\frac{\delta}{H}\right)^{2}\right), \\
& C_{\text {po,secondary }}=\frac{0.038+0.41 \tanh (1.20 \delta / H)}{\sqrt{\cos \gamma}(C R)(H / C)^{0.55}\left(C \cos \alpha_{2} / C_{\mathrm{ax}}\right)^{0.55}} .
\end{aligned}
$$

\section{Summary and Conclusions}

This paper investigates the effectiveness of an active tip clearance control method based on tip air injection at design and off-design incidences. A total of three incidence angles are investigated, which are $-7.4^{\circ}, 0^{\circ}$, and $7.6^{\circ}$ relative to the design value. The total pressure losses at the cascade exit and the heat transfer condition on the blade tip surface, together with the tip clearance mass flow and blade loading are studied using numerical results.

The main conclusions based on the numerical simulations are listed as follows.

(1) At all the incidences, tip injection can reduce total losses at the cascade exit. Losses become less sensitive to the incidence angle when air injection is active.
(2) Around the blade tip regions, the lower-pressure zone on the suction surface decreases in size with the introduction of injection, due to the reduced tip clearance vortex at all the design and off-design incidences.

(3) With injection, at all incidences, the heat transfer coefficient is improved significantly on the blade tip surface in the middle and aft parts of the blade. However, compared to the cases without injection, the region with higher heat transfer coefficients expands in the front part of the blade.

(4) Due to the obstruction by tip injection, tip clearance mass flow rate decreases dramatically and is affected little by the incidence angle.

(5) Tip injection is proved to be an effective method of controlling tip clearance flow, even at off-design conditions.

(6) The indirect empirical correlation proposed by Benner can perform well in predicting the tip clearance losses at design and off-design conditions, no matter whether air injection is active or not.

\section{Nomenclature}

C: $\quad$ Blade true chord

$C_{a x}$ : Blade axial chord

$C_{\mathrm{p}}:$ Static pressure coefficient

$$
C_{\mathrm{p}}=\left(P-P_{\mathrm{ave}, 1}\right) /\left(0.5 \rho \mathrm{V}_{\mathrm{ave}, 1^{2}}\right)
$$


TABLE 3: Empirical correlations of the tip clearance losses.

Prediction method

The tip clearance losses coefficient

Denton [22]

$$
\begin{aligned}
C_{\mathrm{po}, \text { tip }} & =\frac{2 \mathrm{C}_{\mathrm{D}} \tau \mathrm{C}}{H s \cos \alpha_{2}} \int_{0}^{1}\left(\frac{V_{\mathrm{s}}}{V_{2}}\right)^{3}\left(1-\frac{V_{\mathrm{p}}}{V_{\mathrm{s}}}\right) \sqrt{\left(1-\left(\frac{V_{\mathrm{p}}}{V_{\mathrm{s}}}\right)^{2}\right)} \frac{d z}{C} \\
C_{\mathrm{po}, \text { tip }} & =C_{\mathrm{po}, \text { total }}-C_{\mathrm{po}, \text { profile }}-C_{\mathrm{po} \text { secondary }}
\end{aligned}
$$

Benner et al. $[23,24]$

$$
\begin{aligned}
& C_{\text {po,profile }}=\frac{P_{o, \text { mid }, 1}-P_{o, \text { mid, } 2}}{P_{o, \text { mid }, 2}-P_{\text {mid }, 2}}\left(1-\frac{0.10\left(F_{t}\right)^{0.79}}{\sqrt{\mathrm{CR}}(H / C)^{0.55}}-32.70\left(\frac{\delta}{H}\right)^{2}\right) \\
& C_{\text {po,secondary }}=\frac{0.038+0.41 \tanh (1.20 \delta / H)}{\sqrt{\cos \gamma}(C R)(H / C)^{0.55}\left(C \cos \alpha_{2} / C_{\mathrm{ax}}\right)^{0.55}} \\
& C_{\text {po,tip }}=2 K_{\mathrm{E}} C_{\mathrm{D}}\left(\frac{\tau}{H}\right)\left(\frac{C}{s}\right) C_{\mathrm{L}}^{1.5}\left(\frac{\cos ^{2} \alpha_{2}}{\cos ^{3} \alpha_{\mathrm{m}}}\right)+\zeta K_{\mathrm{G}}\left(\frac{C}{s}\right)\left(\frac{C}{H}\right) C_{\mathrm{D}} C_{\mathrm{L}}{ }^{0.5}\left(\frac{1}{\cos \alpha_{\mathrm{m}}}\right) \\
& C_{\text {po,tip }}=0.5\left(\frac{\tau}{H}\right)\left(\frac{C}{s}\right)^{2} C_{\mathrm{L}}^{2}\left(\frac{\cos ^{2} \alpha_{2}}{\cos ^{3} \alpha_{\mathrm{m}}}\right)\left(\frac{\mathrm{Re}}{2 \times 10^{5}}\right)^{-0.2} \\
& C_{\text {po,tip }}=0.47\left(\frac{C}{H}\right)\left(\frac{\tau}{C}\right)^{0.78} C_{\mathrm{L}}^{2}\left(\frac{\mathrm{C}}{\mathrm{s}}\right)^{2}\left(\frac{\cos ^{2} \alpha_{2}}{\cos ^{3} \alpha_{\mathrm{m}}}\right) \\
& \frac{\Delta \eta}{\eta_{\tau=0}}=0.93\left(\frac{\tau}{H}\right)\left(\frac{1}{\cos \alpha_{2}}\right)\left(\frac{R_{\text {tip }}}{R_{\text {mean }}}\right)
\end{aligned}
$$

Yaras \& Sjolander [25]

Ainley \& Mathieson [26]

Dunham \& Came [27]

Kacker \& Okapuu [28]

$C_{\mathrm{po}}$ : Total pressure loss coefficient $C_{\mathrm{po}}=\left(\bar{P}_{o, 1}-P_{o}\right) /\left(0.5 \rho V_{\mathrm{ave}, 1}{ }^{2}\right)$

$C_{\mathrm{pt}}$ : Total pressure loss coefficient used in Figure 2(a) $C_{\mathrm{pt}}=\left(P_{o}-P_{s 3}\right) /\left(P_{o, s 1}-P_{s 3}\right)$

$C_{\mathrm{D}}$ : Discharge coefficient

$C_{\mathrm{L}}:$ Lift coefficient

CR: Convergence ratio $C R=\cos \alpha_{1} / \cos \alpha_{2}$

$F_{t}$ : Tangential loading parameter $F_{t}=2\left(s / C_{\mathrm{ax}}\right) \cos ^{2} \alpha_{\mathrm{m}}\left(\tan \alpha_{1} u-\tan \alpha_{2}\right)$

$h$ : Heat transfer coefficient

$H$ : Blade span

$i$ : Incidence angle

$m$ : Mass flow

$m_{\text {in }}$ : Mass flow into tip clearance

$m_{\text {out }}$ : Mass flow out of the tip clearance

P: $\quad$ Static pressure

Po: Total pressure

$P_{o, s 1}$ : Total pressure at the inlet of "LISA" 1.5-stage axial turbine

$P_{s 3}:$ Static pressure at the exit of the second stator of "LISA" 1.5-stage axial turbine

PS: Pressure surface

R: Radius

SS: Suction surface

s: $\quad$ Blade pitch

$\mathrm{V}$ : Velocity

$Y+$ : Non-dimensional wall distance

$\alpha$ : $\quad$ Flow yaw angle measured from the axial direction

$\gamma: \quad$ Stagger angle measured from axial direction

$\rho: \quad$ Density

$\eta: \quad$ Efficiency

t: $\quad$ Tip clearance height

$\zeta$ : $\quad$ Inlet endwall boundary layer displacement thickness

\section{Subscripts:}

1: Cascade inlet

2: Cascade exit

ave: Mass-averaged value

$i$ : Tip injection

$m$ : Main passage flow

mid: Value at $50 \%$ span, pitchwise-averaged

p: $\quad$ Pressure surface

$s: \quad$ Suction surface

\section{References}

[1] T. C. Booth, P. R. Dodge, and H. K. Hepworth, "Rotor-tip leakage_-part 1: basic methodology," Journal of Engineering for Power, vol. 104, no. 1, pp. 154-161, 1982.

[2] D. E. Metzger and K. Rued, "The influence of turbine clearance gap leakage on passage velocity and heat transfer near blade tips-part I: sink flow effects on blade pressure side," Journal of Turbomachinery, vol. 111, no. 2, pp. 284-292, 1989.

[3] A. K. Saha, S. Acharya, R. Bunker, and C. Prakash, "Blade tip leakage flow and heat transfer with pressure-side winglet," International Journal of Rotating Machinery, vol. 2006, Article ID 17079, 15 pages, 2006.

[4] D. Dey and C. Camci, "Aerodynamic tip desensitization of an axial turbine rotor using tip platform extensions," ASME paper no. 2001-GT-0484, 2001.

[5] G. S. Azad, J.-C. Han, and R. J. Boyle, "Heat transfer and flow on the squealer tip of a gas turbine blade," ASME paper no. 2000-GT-195, 2000.

[6] R. S. Bunker and J. C. Bailey, "Blade tip heat transfer and flow with chordwise sealing strips," in Proceedings of the International Symposium on Transport Phenomena and Dynamics of Rotating Machinery (ISROMAC '00), pp. 548553, Honolulu, Hawaii, USA, 2000. 
[7] B. Mischo, T. Behr, and R. S. Abhari, "Flow physics and profiling of recessed blade tips: impact on performance and heat load," Journal of Turbomachinery, vol. 130, no. 2, Article ID 021008, 8 pages, 2008.

[8] J. Tallman and B. L. Lakshminarayana, "Methods for desensitizing tip clearance effects in turbines," ASME paper no. 2001GT-0486, 2001.

[9] G. Morphis and J. P. Bindon, "The performance of a low speed one and a half stage axial turbine with varing rotor tip clearance and tip gao geometry," ASME paper no. 94-GT-481.

[10] L. I. Wei, Q. Weiyang, and X. U. Kaifu, "Numerical simulation of tip clearance control in axial turbine-part 1: active flow control injection from turbine blade tip," ASME paper no. GT2008-50084

[11] N. M. Rao and C. Camci, "Axial turbine tip desensitization by injection from a tip trench-part 1: effect of injection mass flow rate," in Proceedings of the ASME Turbo Expo: Power for Land, Sea and Air Conference, pp. 1075-1088, 2004, ASME paper no. GT2004-53256.

[12] N. M. Rao and C. Camci, "Axial turbine tip desensitization by injection from a tip trench-part 2: leakage flow sensitivity to injection location," in Proceedings of the ASME Turbo Expo: Power for Land, Sea and Air Conference, pp. 1089-1098, 2004, ASME paper no. GT2004-53258.

[13] P. J. Newton, G. D. Lock, S. K. Krishnababu, et al., "Aerothermal investigation of tip leakage flow in axial flow turbines-part III: tip cooling," in Proceedings of the ASME Turbo Expo: Power for Land, Sea and Air, vol. 4, pp. 317-327, 2007, ASME paper no. GT2007-27368.

[14] M. Hamik and R. Willinger, "An innovative passive tip-leakage control method for axial turbines: linear cascade wind tunnel results," ASME paper no. GT2008-50056.

[15] T. Behr, A. I. Kalfas, and R. S. Abhari, "Control of rotor tip leakage through cooling injection from the casing in a highwork turbine," Journal of Turbomachinery, vol. 130, no. 3, Article ID 031014, 12 pages, 2008.

[16] B. Mischo, A. Bürdet, T. Behr, and R. S. Abhari, "Control of rotor tip leakage through cooling injection from casing in a high-work turbine: computational investigation using a feature-based jet model," in Proceedings of the ASME Turbo Expo: Power for Land, Sea and Air, vol. 6, pp. 1343-1355, 2007, ASME paper no. GT2007-27669.

[17] J. Tallman and B. Lakshminarayana, "Numerical simulation of tip leakage flows in axial flow turbines, with emphasis on flow physics-part I: effect of tip clearance hight," Journal of Turbomachinery, vol. 123, pp. 314-323, 2001.

[18] N. Maosheng and Z. Shusheng, "Tip clearance flow simulation in an axial turbine stage," ISROMAC12-2008-20143.

[19] T. Behr, A. I. Kalfas, and R. S. Abhari, "Unsteady flow physics and performance of a one-and-1/2-stage unshrouded high work turbine," Journal of Turbomachinery, vol. 129, no. 2, pp. 348-359, 2007.

[20] J. P. Bindon, "Pressure distributions in the tip clearance region of an unshrouded axial turbine as affecting the problem of tip burnout," in Proceedings of the International Gas Turbine Conference, Anaheim, Calif, USA, 1987, ASME paper no. 87GT-230.

[21] J. P. Bindon, "The measurement and formation of tip clearance loss," ASME paper no. 88-GT-203.

[22] J. D. Denton, "Loss mechanisms in turbomachines," Journal of Turbomachinery, vol. 115, no. 4, pp. 621-656, 1993.
[23] M. W. Benner, S. A. Sjolander, and S. H. Moustapha, "An empirical prediction method for secondary losses in turbines-part I: a new loss breakdown scheme and penetration depth correlation," Journal of Turbomachinery, vol. 128, no. 2, pp. 273-280, 2006.

[24] M. W. Benner, S. A. Sjolander, and S. H. Moustapha, "An empirical prediction method for secondary losses in turbines-part II: a new secondary loss correlation," Journal of Turbomachinery, vol. 128, no. 2, pp. 281-291, 2006.

[25] M. I. Yaras and S. A. Sjolander, "Prediction of tip-leakage losses in axial turbines," Journal of Turbomachinery, vol. 114, no. 1, pp. 204-210, 1992.

[26] D. G. Ainley and G. C. R. Mathieson, "A method of performance estimation for axial-flow turbines," Tech. Rep. ARC, R\&M 2974, British Aeronautical Research Council, 1951.

[27] J. Dunham and P. M. Came, "Improvements to the AinleyMathieson method of turbine performance prediction," Journal of Engineering for Power, vol. 92, no. 3, pp. 252-256, 1970.

[28] S. C. Kacker and U. Okapuu, "A mean line prediction method for axial flow turbine efficiency," Journal of Engineering for Power, vol. 104, no. 1, pp. 111-119, 1982. 

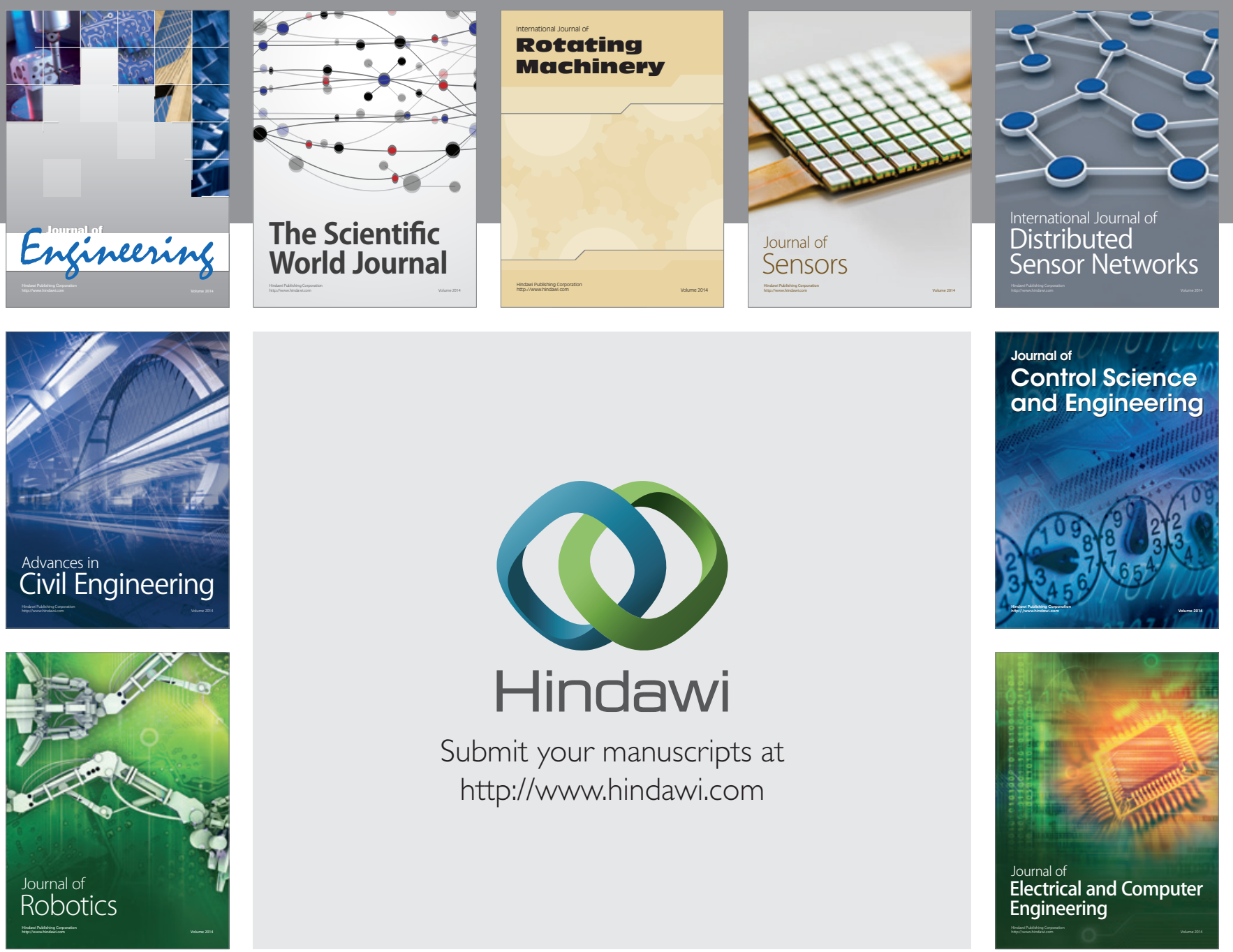

Submit your manuscripts at

http://www.hindawi.com
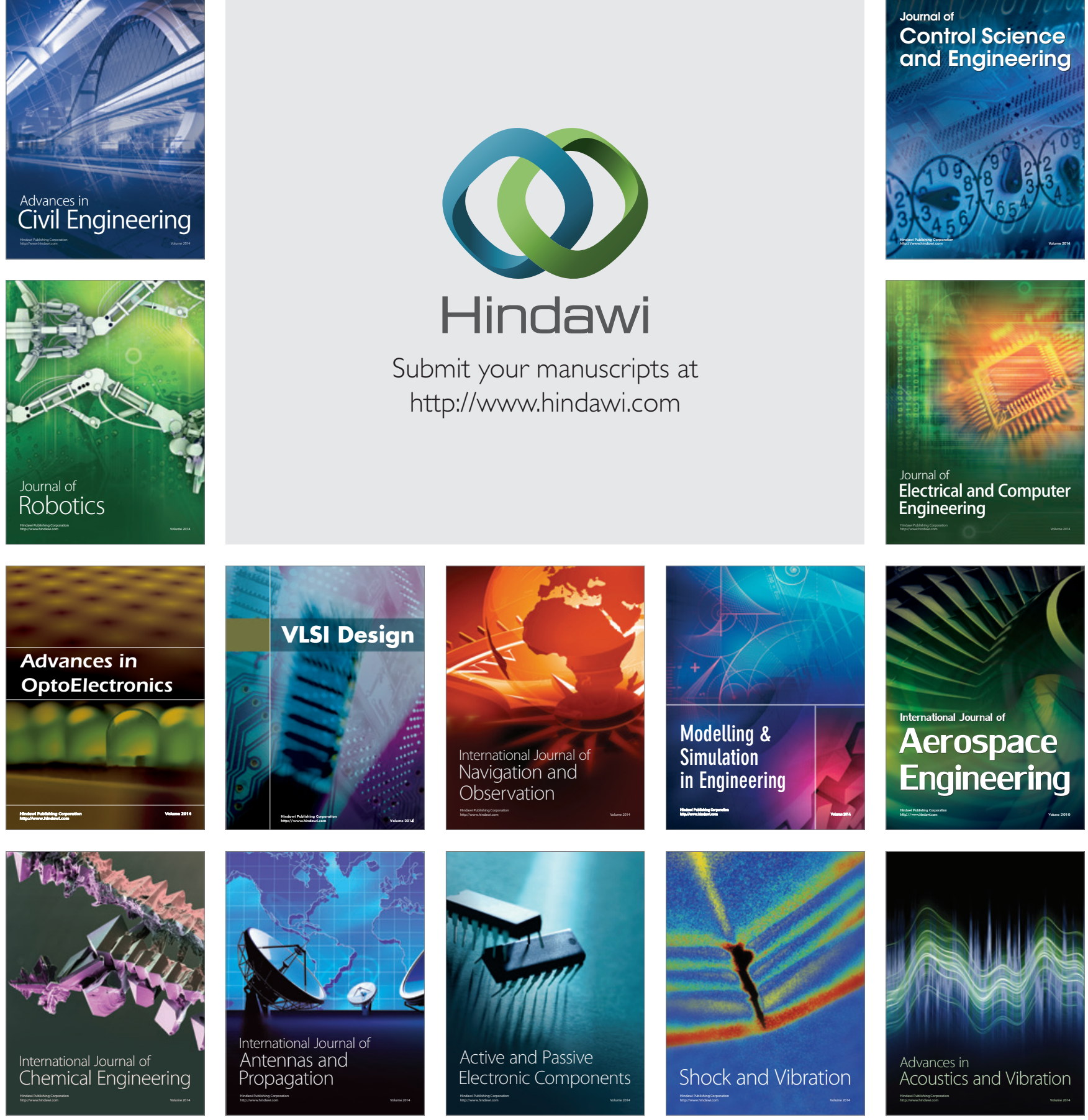